https://unars.ac.id/ojs/index.php/pgsdunars/index

\title{
PENERAPAN METODE PEMBELAJARAN BUZZ GROUP DALAM MENINGKATKAN HASIL BELAJAR SISWA PADA MATA PELAJARAN MATEMATIKA KELAS II SD NEGERI 2 SELETRENG KECAMATAN KAPONGAN KABUPATEN SITUBONDO TAHUN PELAJARAN 2018/2019
}

\author{
Aenor Rofek ${ }^{1}$, Lailatus Zehro ${ }^{2}$ \\ 1,2 PGSD, FKIP Universitas Abdurachman Saleh Situbondo \\ Correspondence e-mail: aenor_rofek@unars.ac.id,
}

Received: March 10, $2021 \quad$ Revised: March 16, 2021 Accepted: March 15, 2021

\begin{abstract}
ABSTRAK
Penelitian ini bertujuan untuk mendekripsikan penerapan metode pembelajaran buzz group dalam meningkatkan hasil belajar siswa pada mata pelajaran matematika kelas ii sd negeri 2 seletreng kecamatan kapongan kabupaten situbondo tahun pelajaran 2018/2019. Jenis penelitian ini adalah penelitian tindakan kelas yang dilakukan pada kondisi normal. Subjek penelitian ini adalah guru kelas II dan siswa kelas II yang berjumlah 15 siswa terdiri dari 8 siswa laki-laki dan 7 siswa perempuan. Penelitian dilaksanakan pada bulan April-Mei 2019 Di SD Negeri 2 Seletreng. Penelitian ini dilaksanakan selama 3 pertemuan mulai dari tanggal 15 April sampai dengan 17 Mei 2019. Data penelitian diperoleh dengan cara observasi, wawancara dan dokumentasi. Observasi digunakan untuk mendapatkan data keterlaksanaan penerapan metode pembelajaran Buzz. Grouppada mata pelajaran Matematika, wawancara digunakan untuk mendapatkan data kegiatan guru dalam perencanaan, pelaksanaan, evaluasi dan penerapan metode pembelajaran Buzz Group pada mata pelajaran Matematika. Setelah itu dilanjutkan dengan uji tes soal yang diberikan oleh guru kepada siswa untuk memperoleh hasil belajar siswa kelas II.
\end{abstract}

Kata Kunci: Metode Buzz Group, Matematika, Penelitian Tindakan Kelas 


\section{PENDAHULUAN}

Pedidikan merupakan suatu kegiatan yang universal dalam kehidupan manusia, karena dimanapun dan kapanpun di dunia terdapat pendidikan. Pendidikan pada hakekatnya merupakan usaha manusia untuk memanusiakan manusia itu sendiri, yaitu untuk membudayakan manusia atau untuk memuliakan kemanusiaan manusia. Untuk terlaksananya pendidikan dengan baik dan tepat, diperlukan suatu ilmu yang mengkaji secara mendalam bagaimana harusnyapendidikan itu di laksanakan.

Ilmu yang menjadi dasar tersebut haruslah yang telah teruji kebenaran dan keampuhannya karenapendidikan merupakan salah satu bidang yang mempunyai peranan besar dalam pembangunan di suatu negara selain bidang ekonomi, politik, keamanan dan sebagainya.Maju mundurnya bangsa banyak di tentukan oleh maju mundurnyapendidikan, oleh karena itu pendidikan harus di laksanakan sebaik-baiknya agar memperoleh hasil yang maksimal.

Menurut (Dirman, 2014: 41), pembelajaran adalah suatu usaha untuk membuat peserta didik belajaratau suatu kegiatan untuk membelajarkan peserta didik. UU No. 20 tahun 2003 tentang Sisdiknas pasal 1 Ayat 20 menyatakan bahwa pembelajaran adalah proses interaksi peserta didik dengan pendidik dansumber belajar pada suatu lingkungan belajar. Kurikulum 2013 adalahkurikulum berbasis kompotensi,pengembangan kurikulum 2013 diarahkan pada pencapaian kompotensi yang dirumuskan dari Standar Kelulusan (SKL).

Menurut (Leoleok Endah Poerwati, 2013:28) kurikulum 2013yaitu kurikulum yang terintegrasi, maksudnya adalah suatu medel kurikulum yang dapat mengintegrasikan skill, themes, concepts, and topics baik dalam bentuk within singel disciplines, across several disciplines and within and across learners.

Dengan kata lain bahwa kurikulum terpadu sebagai sebuah konsep dapat dikatakan sebagai sebuah sistem dan pendekatan pembelajaran yangmelibatkan beberapa disiplin ilmu atau mata pelajaran/bidang studi untuk memberikan pengalaman yang bermakna dan luas kepada peserta didik.

Sekolah merupakan suatu lembaga pendidikan yang khusus dirancang untuk pengajaran para siswa dibawah pengawasan guru. Dalam kaitannya peran guru dalam proses pembelajaran, (Suyono, 2014:187.) melihat ada tiga fungsi utama guru dalam pembelajaran, yaitu sebagai perencana (planner), pelaksana dan pengelola (organizer) dan 
penilai (evaluator). Menurut (Sudjana, 2005:76) berpendapat bahwa metode merupakan perencanaan secara menyeluruh untuk menyajikan materi pembelajaran bahasa secara teratur, tidak ada satu bagian yang bertentangan, dan semuanya berdasarkan pada suatu pendekatan tertentu.

Banyak metode pembelajaran yang telah dikembangkan oleh guru yang pada dasarnya untukmemberikan kemudahan bagi siswa untuk memahami dan menguasai suatu pengetahuan atau pelajaran tertentu. Salah satunya Salah satu upaya yang dilakukan agar siswa aktif dalam proses pembelajaran adalah dengan menerapkan metode yang tepat, seperti metode Buzz Group.

Menurut (Roestiyah, 2001:9) Pembelajaran Buzz Group adalah suatu kelompok besar yang dibagi menjadi 2 (dua) sampai 8 (delapan) kelompok yang lebih kecil sehingga jika diperlukan kelompok kecil ini diminta untuk melaporkan hasil diskusi yang mereka lakukan kepada kelompok besar.

(Hasibuan, 1995:21) hasilbelajar yang diharapkan dalam metode Buzz Group yaitu siswa membandingkan persepsinya yang mungkin berbeda-beda tentang bahan pelajaran, membandingan informasi yang diperoleh masing-masing sehingga siswa dapat saling memperbaiki pengertian, persepsi, informasi, interpretasi sehingga dapat dihindarkan kekeliruan.

Jadi, dapat disimpulkan bahwa metodediskusi Buzz Group adalah suatu metode yang membagi kelas besar menjadi kelompok-kelompok kecilyang terdiri dari 3-4 siswa untuk memecahkan masalah yang diberikan guru. Hasil diskusi ditulis oleh salah satu siswa dan dikumpulkan ke guru.

Matematika merupakan salah satu mata pelajaran yang diajarkan mulai dari tingkat SD sampai tingkat SMA. (Sundayana, 2013:3) mengemukakan hakikat Matematika yaitu "Mathematic is the abstract science of space and number". Matematika adalah ilmu abstrak mengenai ruang dan bilangan. Mata pelajaran matematika pada tingkat sekolah dasar meliputi aspek bilangan, geometri dan pengolahan data (Depdiknas, 2006).

Berdasarkan hasil pengamatan di SD Negeri 2 Seletreng, bahwa nilai Matematika siswa tersebut masih terbilang memprihatinkan. Ada beberapa masalah yang dapat diidentifikasi yaitu metode pembelajaran yang digunakan oleh guru yaitu model konvensional selama kegiatan belajar mengajar di kelas kurang menarik, kurangnya interaksi antara guru dengan siswa selama kegiatan belajar mengajar di kelas dan rendahnya nilai hasil belajar siswa yang dimiliki guru 
bahwa hasil pengamatan dari sebelum tindakan diperoleh rata-rata aktivitas belajar siswa kategori rendah. Bahwa dari 15 orang siswa kelas II SD Negeri 2 Seletreng. Kecamatan Kapongan KabupatenSitubondo, tercatat hasil belajarsiswa 6 orang siswa (45 $\%$ ) saja yangmemperoleh nilai 71-100, selebihnya 5 orang siswa (30\%) memperoleh nilai $61-70$, dan 4 orang (25\%) siswa yang lain yang memperoleh nilai antara 40-60. Hal ini menunjukkan siswa kelas II SD Negeri 2 Seletreng belum mencapai ketuntasan belajar khususnya dalam mengidentifikasipecahanmenggunakan benda konkret dalam kehidupan sehari-hari. Siswa tersebut dapat dikatakan tuntas apabila memperoleh nilai 65 keatas sesuai dengan Kriteria Ketuntasan Minimal (KKM) di SDN 2 Seletreng.

\section{METODE PENELITIAN}

\section{Subjek Penelitian}

Jenis penelitian ini adalah Penelitian Tindakan Kelas (Classroom Action Reseach). Penelitian ini dilakukan di kelas II SD NEGERI 2 SELETRENG, waktu penelitian ini telah dilakukan mulai tanggal 16 April - 11 Mei 2019 pada semester ganjil Tahun Pelajaran 2018/2019.

\section{RENCANA TINDAKAN}

Dalam Penelitian ini rencana tindakan pada Penelitian Tindakan Kelas (PTK) adalah menggunakan beberapa tahapan yang meliputi: tahap perencanaan, pelaksanaan tindakan, pengamatan, dan refleksi. Penelitian ini dilaksanakansebanyak dua siklus, siklus 1 sebagai wujud perbaikan tetapi jika masih ada yang belum tuntas dilakukan siklus 2 sebagai penguatan dari perbaikan kedua. Sedangkan yang diteliti adalah hasil belajar siswa dalam pembelajaran Matematika pada Tema 7 Kebersamaan melalui metode Pembelajaran Buzz Group.

\section{a. Pra Siklus}

Tahap pra siklus dilakukan untuk mengidentifikasi masalah yang terjadi didalam kelas yang mempengaruhi tingkat hasil bela1jar siswa.

\section{b. Siklus I}

Sesuai dengan kaidah penulisan PTK, maka tahapan pelaksanaan PTK siklus 1 ini dimulaidari tahap perencanaan, tindakan,pengamatan, dan reflex 


\section{c. Siklus II}

1. Dalam siklus ini menggunakan beberapa tahapan, 1)Tahap Perencanaan Tindakan 2) Tahap Refleksi d a n 3 ) Tahap Pengamatan

\section{Faktor Yang Diteliti}

\section{a. Faktor Guru}

Menguasai suatu metode mengajar dalam proses pembelajaran merupakan hal yang sangat penting

\section{b. Faktor siswa}

Belajar disekolah merupakan sebuah bentuk tindakan pembelejaran yang diberikan oleh guru kepada siswa, banyak variasi mengajar yang dilakukan oleh guru ketika proses pembelajaran salah satunya adalah menggunakan metode pembelajaran, namun ditempat yang saya teliti yaitu di SD Negeri 2 Seletreng kacamatan kapongan kabupaten situbondo, guru hanya menggunakan metode konvesioner yang menyababkan proses belajar mengajarnya hanya monoton dan membuat siswa kurang bersemangat dan cenderung siswa tidak giat untukmenerima pelajaran.

Hal ini dapat menyebabkan hasil belajar yang kurang bagi siswa, khususnya dalam mata pelajaran matematika yang mana dalam mata pelajaran tersebut untuk dilaksanakan oleh seorang guru.

Hal ini tentunya atas dasar bahwa penggunaan sebuah metode tidak makan berhasil tanpa adanya kemampuan guru dalam menggunakan atau menerapkan metode tersebut, meskipun kenyataannya metode tersebut baikdan sesuai diterapkan dalampembelajaran.

Banyak siswa yang kurang menyukai karena kesulitan dalam mengerjakan maupun menerima pelajaran.

\section{Teknik dan Alat Perolehan Data}

Teknik pengumpulan data dalamPenelitian Tindakan Kelas (PTK) ini dimaksudkan untuk memperoleh data-data yang relevan dan akurat yang digunakan dengantepat sesuai tujuan penelitian. Teknik pengumpulan data terdiri dari, observasi, wawancara dandokumentasi. 


\begin{tabular}{|l|l|c|c|}
\hline Kompetensi Dasar & Indikator & $\begin{array}{c}\text { No } \\
\text { Soal }\end{array}$ & Taksonomi Bloom \\
\hline $\begin{array}{l}\text { Menjelaskan } \\
\text { menggunakan benda } \\
\text { benda konkret dalam }\end{array}$ & $\begin{array}{l}\text { Siswa dapat } \\
\text { menulisk an } \\
\text { pecahan } \\
\text { dengan }\end{array}$ & 1,2 & $\mathrm{C} 1$ \\
\hline
\end{tabular}

\section{Indikator Penelitian}

1. Menghitung nilai akhir setiapsiklus

Nilai Akhir (NA)

$=$ Jumlah skor total peroleh an $\mathrm{x} 100$

jumlah skor maksimal

a. Nilai evaluasi siklus I

b. Nilai evaluasi siklus II

Nilai evaluasi siklus $I=$ Jumlah skor yang diperoleh x 10

2. Menghitung nilai rata-rata kelas

Nilai rata-rata =

$\frac{\text { Jumlah nilai yang diperoleh seluruh siswa }}{\text { Jumlah siswa }}$

3. Presentase ketuntasan $=$

Jumlah Siswa yang tuntas X 100\% Jumlah seluru siswa

\section{Metode Analisis Data}

1. KKM perseorangan

Seorang siswa dikatakan telah memenuhi standar ketuntasan belajar bila mencapai skor $\geq 65$ dari skor maksimal 100

2. KKM klasikal

Suatu kelas telahdikatakan memenuhi standarketuntasan belajar dikelas tersebut telah mencapai $\geq 75 \%$ dari jumlah siswa yang telah mencapai skor $\geq 65$ skor maksimal. 


\section{HASIL PENELITIAN}

Hasil Pra siklus

\section{Siklus 1}

\begin{tabular}{|c|l|c|}
\hline No & \multicolumn{1}{|c|}{ Nama } & Nilai \\
\hline $\mathbf{1}$ & Achmad Fakhrul & 50 \\
\hline $\mathbf{2}$ & Aisyah Aprilia P & 45 \\
\hline $\mathbf{3}$ & Ayu Agustin & 40 \\
\hline $\mathbf{4}$ & Bahdatul Imania & 40 \\
\hline $\mathbf{5}$ & Faiz Hamdani & 65 \\
\hline $\mathbf{6}$ & Fatiatul Faiza & 50 \\
\hline $\mathbf{7}$ & Moh. Azril Afandi & 60 \\
\hline $\mathbf{8}$ & Muhammad Anis & 65 \\
\hline $\mathbf{9}$ & Muhammad H & 50 \\
\hline $\mathbf{1 0}$ & Muhammad R & 40 \\
\hline $\mathbf{1 1}$ & Muhammad R.A & 40 \\
\hline $\mathbf{1 2}$ & Nadira Eka Wahyuni & 50 \\
\hline $\mathbf{1 3}$ & Putri Aprilia Zakidatul H & 65 \\
\hline $\mathbf{1 4}$ & Yusril Maulana & 50 \\
\hline $\mathbf{1 5}$ & Zainul Idris & $\mathbf{7 5 0}$ \\
\hline & Jumlah & \\
\hline & & \\
\hline
\end{tabular}




\begin{tabular}{|c|l|c|}
\hline No & \multicolumn{1}{|c|}{ Nama } & Nilai \\
\hline $\mathbf{1}$ & Achmad Fakhrul Arifin & 65 \\
\hline $\mathbf{2}$ & Aisyah Aprilia Putri & 50 \\
\hline $\mathbf{3}$ & Ayu Agustina & 50 \\
\hline $\mathbf{4}$ & Bahdatul Imania & 50 \\
\hline $\mathbf{5}$ & Faiz Hamdani & 75 \\
\hline $\mathbf{6}$ & Fatiatul Faizah & 60 \\
\hline $\mathbf{7}$ & Moh. Azril Afandi & 65 \\
\hline $\mathbf{8}$ & Muhammad Anis & $\mathbf{7 0}$ \\
\hline $\mathbf{9}$ & Muhammad Hilmi & 55 \\
\hline $\mathbf{1 0}$ & Muhammad Ramdan & 50 \\
\hline $\mathbf{1 1}$ & Muhammad Riski Azzam & 50 \\
\hline $\mathbf{1 2}$ & Nadira Eka Wahyuni & 60 \\
\hline $\mathbf{1 3}$ & Putri Aprilia zaidatul H & 70 \\
\hline $\mathbf{1 4}$ & Yusril Maulana & 65 \\
\hline $\mathbf{1 5}$ & Zainul Idris & $\mathbf{8 8 5}$ \\
\hline & Jumlah & \\
\hline
\end{tabular}




\section{Siklus II}

\begin{tabular}{|c|l|c|}
\hline \multicolumn{1}{|c|}{ No } & \multicolumn{1}{|c|}{ Nama } & Nilai \\
\hline $\mathbf{1}$ & Achmad Fakhrul Arifin & 70 \\
\hline $\mathbf{2}$ & Aisyah Aprilia Putri & 70 \\
\hline $\mathbf{3}$ & Ayu Agustina & 65 \\
\hline $\mathbf{4}$ & Bahdatul Imania & 80 \\
\hline $\mathbf{5}$ & Faiz Hamdani & 80 \\
\hline $\mathbf{6}$ & Fatiatul Faizah & 70 \\
\hline $\mathbf{7}$ & Moh. Azril Afandi & 75 \\
\hline $\mathbf{8}$ & Muhammad Anis & 65 \\
\hline $\mathbf{9}$ & Muhammad Hilmi & 65 \\
\hline $\mathbf{1 0}$ & Muhammad Ramdan & 60 \\
\hline $\mathbf{1 1}$ & Muhammad Riski A & 65 \\
\hline $\mathbf{1 2}$ & Nadira Eka Wahyuni & 80 \\
\hline $\mathbf{1 3}$ & Putri Aprilia zaidatul H & 70 \\
\hline $\mathbf{1 4}$ & Yusril Maulana & 60 \\
\hline $\mathbf{1 5}$ & Zainul Idris & $\mathbf{1 , 0 4 0}$ \\
\hline & Jumlah & \\
\hline & & \\
\hline
\end{tabular}

\section{Pembahasan Pra-Siklus}

Berdasarkan dari kegiatan prasiklus yang sudah dilakukan banyak sekali hal-hal yang perludiperbaiki yaitu dari segi hasil belajar siswa yang masih rendahdibawah KKM dimana dari 15 siswa di kelas II rata-rata nilai yang diperoleh yaitu 50 dan presentase ketuntasannya hanya $20 \%$ dan sisi lain dapat dilihat dari metode cerama yang guru gunukan yaitu cenderung monoton, pasif dan juga membosankan bagi siswa, kurang adanya interaksi yang bersifat dua arah, dan bahkan kebanyakan guru hanya mengejar target materi dari pada meningkatkan motivasi belajar siswa. 


\section{Siklus I}

Hasil yang diperloleh darisiklus I ini siswa mendapatkan nilai rata-rata 59 dimana nilai tersebut masih kurang dari kriteria ketuntasansekolah namun juga sudah mengalami peningkatan dari kondisi awal pada pra-siklus yaitu kondisi awal siswa mendapatkan nilai rata-rata 50 dan presentase ketuntasan $20 \%$ dan siklus I siswa mendapatkan nilai rata-rata 59 dan presentase ketuntasan $40 \%$.

\section{Siklus II}

Dalam siklus ke II ini siswa sudah berani mempresentasikan mempresentasikan hasil belajarnya didepan teman-teman lainnya yaitu seperti siswa menjelaskan hasil yang sudah didiskusikan dimasing-masing kelompok.

Hal ini juga mendorong hasil belajar siswa yang mulai baik dari sebelumnya dimana pada prasiklus rata-rata nilai yang diperoleh yaitu 50 dan presentase ketuntasan $20 \%$ dilanjut dengan kegiatan siklusI yaitu memperoleh nilai 59 dengan presentase ketuntasan $40 \%$ dalam siklus inisiswa sudah mulai mendapat peningkatan hasil belajar namun masih belum mencapai target ketuntasan yang sudah ditentukanoleh sekolah yaitu 65 namun pada siklus ke II hasil belajar siswa sudah mencapai nilai KKM yang ditentukan dengan perolehan nilai rata-rata 69 dengan presentasiketuntasan $87 \%$.

\section{KESIMPULAN}

Melalui penerapan metode pembelajaran Buzz Group dalam meningkatkan hasil belajar siswa pada mata pelajaran matematika siswa kelas II SD Negeri 2 Seletreng. Hal ini dapat dilihat dari kondisi awal rata-rata pada saat kegiatan prasiklus yaitu 50 dengan presentase ketuntasa 20\%. Setelah dilakukan penelitian pada siklus I menggunakan pendekatan metode pembelajaran Buzz Group pada materi operasi hitung pecahan mengalami peningkatan dengan nilai rata-rata 59 dengan persentase ketuntasan siswa mencapai $40 \%$. Kemudian dilanjutkan ke siklus II hasil belajar siswa mengalami peningkatan, pada siklus II rata-rata peningkatan menjadi 69 dengan persentase ketuntasan siswa mencapai $87 \%$. 


\section{DAFTAR PUSTAKA}

Arikunto. (2013:128). Prosedur Penelitian. Jakarta: Bumi askara

Depdiknas. 2006. StandarKompetensi dan kompetensi Dasar Mata PelajaranMatematika Sekolah Dasar danMadrasah Ibtidaiyah. Jakarta:Depdiknas.

Dirman. Juarsih,cicih. 2014. Teori belajar dan Prinsip-prinsip pembelajaran yang mendidik.Jakarta: Rineka Cipta.

Hasibuan. (1995:20-21). Belajar danPembelajaran. Jakarta.Rieneka.

Hamalik, Oemar. (2012:28). Proses Belajar Mengajar. Jakarta: PT.Bumi Aksara.

Heruman. (2007:1-2). Model Pembelajaran Matematika di Sekolah Dasar. Bandung: PT.

Remaja Rosdakarya.

Sundayana, Rostina. (2013:3). Mediapembelajaran Matematika. Bandung:Alfabeta.

Surjadi. (1989:34-39). PenerapanMetode Buzz Group Untuk Meningkatkan Hasil Belajar

Siswa. Jurnal PendidikanDasar. : 
62|J UR N A L IKA V O L 9 No. 1 J U N I 20021 